\title{
Mediació intercultural i institucions escolars: l'exemple del Quebec
}

\section{Núria Llevot i Calvet}

Universitat de Lleida. Departament de Pedagogia i Psicologia

nllevot@pip.udl.es

\section{Resum}

L'increment de la multiplicitat cultural ha comportat que, en diversos països, s'elaborin diferents actuacions per aproximar posicions i millorar la comunicació entre progenitors i professionals de les institucions escolars, així com per facilitar l'adaptació del currículum a la diversitat cultural. Una de les opcions preses, amb cert èxit però no exempta d'errors, és la dels anomenats "mediadors interculturals». Una societat on aquesta figura, amb els noms d'agents de liaison i de milieu, s'ha desenvolupat és el Quebec. L'estudi dels seus encerts i limitacions, específicament a les institucions escolars, creiem que pot ser un referent a partir del qual cal reflexionar, atès el notable increment d'aquesta pràctica a Catalunya.

Paraules clau: mediador intercultural, negociació, famílies minoritàries, educadors, institucions escolars, ciutadania.

\section{Abstract. Intercultural mediation and scholar institutions: the case of Québec}

The increase of the cultural diversity has behaved that, in different countries, different performances are elaborated to approach positions and to improve the communication between progenitors and professionals of the school institutions, as well as to facilitate the adaptation of the curriculum to the cultural diversity. One of the chosen options, with certain success but it doesn't exempt of errors, it is that of the compound numbers intercultural mediators. A society where this figure, with the names agents de liaison and of milieu, it has been developed it is the Quebec. The study of their successes and limitations, specifically in the school institutions, we believe that it can be a with respect to leaving of the one which to meditate given the notable increment of this practice in Catalonia.

Key words: Intercultural mediator, negotiation, minority progenitors, educators, schools, citizenship.

\section{Sumari}

1. Introducció 3. A tall de reflexions

2. L'experiència dels agents de mediació Bibliografia 


\section{Introducció}

$\mathrm{Al}$ Quebec es presta especial atenció a la participació dels pares en la institució escolar - així, per exemple, cada vegada s'atorga més poder als centres educatius, com mostra la reforma que s'hi ha portat a terme (Ministère de l'Éducation, 1997) - igual que a l'estudi dels factors que hi intervenen. Les relacions entre l'escola i la comunitat es consideren un factor de gran importància en l'educació de l'alumnat, com també una correcta educació exigeix el coneixement del medi en què es viu, així com la seva representació en la vida real. Aquests principis, inspiradors de nombroses intervencions governatives, tenen com una de les seves concrecions prioritàries afavorir la participació dels pares en la vida escolar. Una d'aquestes experiències és la mediació intercultural, amb la qual es treballa des de fa anys per donar resposta a la dificultat que té l'organització escolar per adaptar el currículum i els serveis que presta a uns usuaris cada vegada més diversos culturalment, així com incentivar la participació dels progenitors en els centres educatius. Les persones que s'encarreguen d'aquesta tasca són els anomenats agents de liaison i agents de milieu. Amb l'ànim de conèixer l'experiència quebequesa en el camp de la mediació intercultural a les institucions escolars, pel que podria portar al recentment encetat interès a Espanya, vàrem realitzar dues estades de recerca per analitzar, documentalment i empíricament, la cara i la creu d'aquesta intervenció. A continuació, seguint la lògica presentada, s'exposa la síntesi de l'anàlisi teòrica i empírica d'aquest projecte. En primer lloc, a partir dels pocs treballs rellevants sobre la qüestió, presentarem el desenvolupament dels agents al Canadà tot comparant diverses experiències de grans ciutats, per passar posteriorment a aprofundir en l'experiència quebequesa. Aquesta sí, complementant estudis aliens i el propi.

\section{L'experiència dels agents de mediació}

Com hem avançat, al Quebec, davant la necessitat d'establir una comunicació fluida entre el centre i les minories (col-lectius i pares), apareix l'agent de relació o de mediació, creat inicialment per la Comissió d'Escoles Protestants per resoldre els problemes de racisme als centres docents (concretament, de grups d'alumnes antillans i africans) als inicis de la dècada dels setanta (Garreta, 2000). Aquesta figura és creada per millorar la situació dels alumnes de minories culturals, establir contactes entre l'escola i els pares que afavoreixin la participació d'aquests darrers en les diverses activitats i sensibilitzar els agents escolars en la diversitat cultural. Posteriorment, la Comissió Catòlica també utilitzà aquesta figura. Això sí, no en totes les institucions aquest agent realitza el mateix paper: pot estar associat a una minoria específica $i$ atendre els diferents centres d'una comissió; estar adscrit a una escola i ocupar-se de totes les minories promovent-hi les relacions entre els agents; exercir de professor del Programa d'Ensenyança de Llengües d'Origen (PELO) i actuar com a lligam de comunicació amb els pares que pertanyen a la mateixa minoria; entre altres (Garreta 
i Llevot, 1999). Tot i que no tots els models anteriors estan del tot definits i, a més, els dos primers són imprecisos i generen dependència dels actors escolars i dels pares vers el mediador (Helly, 1996), les intervencions realitzades són considerades molt eficaces. Per exemple, la generalització dels serveis dels agents, demanada pel medi escolar i pels grups ètnics, és objecte d'anàlisi en l'informe Latif (Latif, 1989), que, fent un breu repàs de la valoració d'aquesta figura des del seu inici, descrivia l'estat dels serveis educatius dirigits, específicament, a la clientela multiètnica de les escoles del Quebec i, a la vegada, proposava canvis en funció de les seves necessitats. Així mateix, presentava una anàlisi global de les relacions entre els pares de les minories ètniques i l'escola pluriètnica, destacant el resultat positiu obtingut per certes escoles que disposaven dels serveis dels agents. Aquest informe, titulat L'école québécoise et les communautés culturelles, resumia, detalladament, tant el paper i els encàrrecs confiats a aquests professionals com les ambigüitats lligades a aquesta funció, encara de creació molt recent - l'any 1988. Tot reconeixent que aquesta fórmula respon adequadament a certes necessitats locals, aquesta anàlisi no en recomanava l'extrapolació, que depenia d'un finançament ministerial; ni la seva permanència, que qualificava d'inadequada en el context d'una evolució ràpida de la clientela escolar. En aquest domini, com en altres que fan referència a les relacions interculturals a l'escola i la participació de pares de minories ètniques, l'informe Latif suggeria que el Ministeri d'Educació del Quebec mantingués el seu suport financer a les iniciatives locals, sense participar d'aquesta generalització.

Anys més tard, els gestors entrevistats en l'estudi de Mc Andrew i Hardy (1992) explicaren l'origen d'aquesta figura recordant dos incidents: un, les confrontacions entre diferents grups ètnics en una escola secundària del nordest de Montreal el 1983; l'altre, la necessitat, reiterada des de diferents grups, d'aproximar-se a les diverses comunitats culturals, en particular a l'educació primària. La discussió entre els gestors va comportar un programa pilot que implicava els professors del PELO que van ser els pioners a implementar aquesta mesura. Les direccions de les escoles, per la seva part, rebien cada cop un nombre més elevat d'infants al.lòfons en les seves classes i demanaven una ajuda suplementària per respondre a les necessitats específiques d'adaptació escolar d'aquesta nova clientela. La dificultat d'establir una comunicació, verbal i escrita, va ser el primer problema que calia resoldre, perquè era evident que l'equip de l'escola, amb els seus propis mitjans, no podia comunicar-se facilment amb els pares de llengua cambotjana, criolla, portuguesa, etc. (i unes altres de menys conegudes). Els docents comprenien que s'havia de fer quelcom davant un problema de comunicació que impedia desenvolupar bé la tasca encomanada, tant amb els alumnes com amb els pares: amb els alumnes, tot i que anaven a la classe d'acollida, no sempre era suficient, ja que passaven a l'aula ordinària sense conèixer adequadament la llengua ni les seves interpretacions - la seva adaptació al medi escolar no era un cosa adquirida tan ràpidament com es necessitava-; pel que fa als progenitors, no van sol.licitar formalment aquest servei, sinó que, per contra, demanaven ajuda contí- 
nua als serveis dels docents del PELO, que els ajudaven voluntàriament, fet que va provocar l'acceleració de la implantació de la mesura. En síntesi, aquest servei fou sol-licitat des de la base i recomanat pels equips directius dels centres escolars.

En síntesi, la figura de l'agent va ser creada amb la intenció de respondre a les necessitats de comunicació entre escola i pares, així com amb tota la comunitat educativa, fet que comporta que l'agent hagi de respondre a moltes exigències d'una gran heterogeneïtat de "clients» (pares, educadors, administradors, representants ètnics $i$, també, alumnes). Tal com afirma Laperrière (1983), l'agent havia d'intervenir en situacions molt diferents, les quals exigeixen metodologies variades (resoldre problemes dels infants i pares, ser consultat per la Comissió Escolar, afavorir l'aproximació de les famílies de minories ètniques amb la institució escolar, servir d'intèrpret perquè es poguessin comunicar els educadors i els pares, etc.). A més, d'altres documents més recents (Mc Andrew, 1993) relaten el treball d'aquest professional afirmant que pren part dels diversos projectes psicopedagògics realitzats sobre el medi escolar.

\subsection{L'experiència de l'agent quebequès en el marc d'altres actuacions semblants del Canadà}

L'amplitud dels problemes que sorgeixen a l'escola multicultural, les pressions dels grups que representen diverses associacions ètniques, religioses i culturals, així com una autocrítica del sistema escolar portaren a la recerca de solucions vàlides per millorar la integració escolar dels grups etnoculturals presents a la societat. En aquest context, els agents del Canadà (que són anomenats de diferent manera segons la ciutat on intervenen: agents de liaison o agents de milieu, a Montreal; School Community Relation Officer or Worker o Multicultural Consultant, a Toronto, i Multicultural School Worker o Multicultural HomeSchool Worker, a Vancouver) configuren una nova generació d'interventors escolars, amb feina imprecisa, ja que han de respondre a necessitats mal definides però urgents que presenta el sistema escolar. Reben diferents noms, però, al marge de la particularitat dels apel.latius, constitueixen una nova figura professional per donar resposta a una sèrie de necessitats del sistema educatiu.

Un dels pocs estudis comparatius realitzats al Canadà sobre aquests agents (André Beauchesne, 1987) compara la situació dels agents de mediació existents a les ciutats canadenques de Toronto, Vancouver i Montreal. Aquesta figura es crea a les tres ciutats amb la intenció de millorar les relacions existents entre centre escolar i progenitors, com també pretén garantir la igualtat d'oportunitats de tots els alumnes i democratitzar els centres educatius. Al mateix temps, Beauchesne reconeix que aquest projecte és la resposta a la dificultat que té l'organització escolar per adaptar el seu currículum i els seus serveis a les necessitats d'uns usuaris cada vegada més diversos, particularment en contextos econòmicament desfavorits. Als evidents problemes de comunicació lingüística amb l'alumnat i les famílies minoritàries, s'han d'afegir les dificultats de gestionar aquesta diversitat en el conjunt d'activitats escolars. 
Les funcions que els agents realitzaven a les institucions escolars eren, entre altres: traduir les comunicacions verbals o escrites dels diferents agents de la comunitat educativa; donar a conèixer les característiques, exigències, expectatives i necessitats dels alumnes, dels pares i de l'organització escolar entre els implicats; afavorir la comunicació bidireccional; coordinar i actualitzar els projectes o programes que poden generar una millor relació i enteniment; aconsellar sobre la forma d'integrar la perspectiva intercultural en el currículum; coordinar i actualitzar els projectes susceptibles d'incentivar la participació dels pares a l'escola, i ajudar els alumnes de minories ètniques a integrar-se, harmoniosament, en els centres escolars.

Els resultats de l'estudi d'André Beauchesne indiquen que la naturalesa i la urgència de les necessitats per les quals es van crear aquestes figures professionals impliquen canvis en profunditat en el context escolar, especialment: l'adaptació del currículum escolar a les necessitats dels usuaris per mitjà de la creació de vies de comunicació entre escola i comunitat, particularment entre pares i escola. En les tres ciutats citades es constata l'interès per la lluita a favor de la igualtat d'oportunitats educatives i s'afirma que s'ha d'adaptar el currículum escolar a les característiques socioculturals de l'alumnat, fet que resoldria, per exemple, els problemes de comunicació lingüística o cultural, igual que podria afavorir la millora en els resultats acadèmics. Però, malgrat les coincidències, les ciutats diferencien les funcions d'aquests professionals per mitjà de les demandes i les intervencions que s'han de realitzar. Tot i que el nucli és la millora de la relació entre l'escola i els pares, s'observa una gran quantitat de necessitats de l'organització escolar, el desenvolupament de materials o de projectes pedagògics i la resolució de conflictes interètnics (aquests darrers són, essencialment, la seva tasca principal) als quals es vol donar solució. S'ha de destacar també que les funcions que s'acaben realitzant estaven molt subordinades a les necessitats i exigències de les escoles, com ara: la traducció de missatges, la promoció de la participació en activitats extraescolars, etc., intervencions que limiten la seva participació i la converteixen en merament instrumental, per resoldre tan sols els problemes de funcionament. En un context així, queda com a periferica la resolució del veritable problema: abordar la qüestió del paper dels progenitors en el treball d'adaptació del currículum escolar a les necessitats de la diversitat existent.

En línies generals, els agents ocupen una posició ambivalent: d'una banda, reben un encàrrec global de suscitar canvis d'actituds i de pràctiques, tant per part dels professionals escolars com dels pares respecte a les seves relacions; però, d'altra banda, les seves condicions de feina sovint són precàries, fet que restreny molt les seves possibilitats d'acció, ja que es queden a les ordres dels professionals escolars que decideixen, a l'acabament del curs escolar, si el seu contracte serà renovat $\mathrm{o}$ no. En aquest context, els agents no poden realment realitzar els canvis, ja que no serien contractats (o sols ho farien per fer tasques puntuals), per això han de "satisfer l'organització escolar» a expenses de la implicació de les famílies. 


\subsection{Els agents del Quebec: perfil i funcions}

Centrats al Quebec, en un primer document, Rapport Annuel de l'Opération Renouveau (Comission des Écoles Catholiques de Montréal, 1987), es descriu la tasca de l'agent com una persona que informa els pares i els consulta al mateix temps, que els implica en els aprenentatges dels seus fills; i que cada vegada més, s'accentua el fet que ha de conèixer les característiques socioculturals dels alumnes. En altres documents es desglossa l'apel-latiu que pot acompanyar aquest terme (liaison o milieu): com la memòria L'Énoncé de politique en matière d'immigration et d'intégration (Commission des Écoles Catholiques de Montréal, 1991a), on se subratlla la denominació de l'agent de liaison en les escoles pluriètniques per treballar per al conjunt dels alumnes. De forma secundària, l'agent ha d'esforçar-se per fer conèixer i comprendre el funcionament del centre als pares dels alumnes. Per això, en la memòria Les enfants de milieux défavorisés et ceux des communautés culturelles (Conseil Scolaire de l'Île de Montréal, 1991), dirigida al ministre d'Educació, els objectius de la funció de l'agent de milieu són descrits així: afavorir la integració psicosocial de l'alumne minoritari; familiaritzar l'infant immigrant amb les característiques de la societat quebequesa; sensibilitzar el medi escolar a la riquesa de la diversitat i al respecte de tots els grups ètnics i socials presents a la societat quebequesa; establir lligams entre els pares de les comunitats culturals i la institució escolar; afavorir l'acostament entre famílies quebequeses de vieille souche (de soca-rel) i famílies de les comunitats culturals. A la diversitat de feines, s'hi ajunta una varietat de models: així, a la Comissió d'Escoles Catòliques de Montreal, a primària, la fórmula més freqüent és la dels agents reclutats d'entre els docents del PELO; a secundària, és impossible generalitzar el procés, ja que cada cas és particular.

Marie Mc Andrew i Jean-Yves Hardy (1992), anys més tard que Beauchesne, realitzen un estudi - encarregat per l'Oficina de Relacions Interculturals (ORI) - per avaluar aquesta figura a Montreal. L'estudi mostra que el principal motiu de demanda d'aquest servei és la dificultat de comunicació verbal i escrita entre les diverses comunitats culturals i els actors del sistema escolar. També subratllen necessitats, com ara, per exemple, l'aprenentatge de la llengua francesa per part dels nouvinguts, condició necessària (però no suficient) per a la seva integració al sistema educatiu, ja que també l'alumne immigrant i la seva família han de conèixer la cultura quebequesa contemporània (el clima, els costums, el menjar, els valors, etc.) per integrar-s'hi, així com la resta d'entrevistats afirmen que l'escola hauria d'adaptar-se als nous grups d'alumnes, és a dir, tenir en compte els seus valors, sovint allunyats de la població quebequesa de soca-rel. De l'estudi es desprèn que:

- L'agent, a l'educació primària, és cridat, entre d'altres tasques, per: explicar a les famílies l'avaluació i, més concretament, el contingut del butlletí de notes; fer-los comprendre la importància d'ajudar els infants a casa en els seus estudis; explicar els serveis psicopedagògics que ofereixen els centres; comentar els menjars i la importància d'una dieta equilibrada; informar 
de les mesures especials per atendre la diversitat; fer comprendre el sentit de les festes religioses i culturals del Quebec i la importància de les sortides educatives; explicar els reglaments generals de l'escola (com ara, per exemple, els horaris o el transport escolar), així com les expectatives del professorat sobre els alumnes; descriure i explicar els costums, i afavorir els intercanvis de punts de vista sobre els valors del país d'origen i els del país d'acollida, així com també realitzar el seguiment de cada progenitor per assegurar-se que ho ha entès. A més a més, les intervencions de l'agent es dirigeixen també al centre, a l'inrevés d'abans, per fer comprendre, als docents, al personal no docent i a la direcció, els valors, les creences, etc. de l'alumne i de la seva família a partir del respecte a la seva cultura.

- A l'educació secundària, a la majoria de les intervencions, tot i assemblarse a les d'educació primària, s'hi afegeix que els alumnes estan en l'etapa de l'adolescència i tenen experiències i necessitats diferents. Per això, l'agent ha d'informar l'equip de l'escola, els pares i l'alumne, segons el cas, sobre: les relacions interculturals; les relacions amb la direcció, els pares i els docents; la convivència necessària per viure en un medi pluriètnic; l'adaptació al sistema escolar; els mitjans per prevenir i combatre la violència; el concepte d'autoritat en el nostre sistema; els drets i els deures dels joves; l'assiduïtat escolar; els programes d'estudis; la comprensió de la llei; les relacions de gènere al Quebec; la protecció de la joventut; el respecte als costums i a les religions; la importància per a l'adolescent de desenvolupar una autonomia i una autoestima personal; la importància de participar en les activitats de l'escola pel que fa al procés d'integració social; l'elecció d'una carrera; la droga, i la nutrició equilibrada, entre altres.

Els agents són cridats a realitzar multitud de tasques que depassen el quadre escolar, moltes vegades basades en la confiança que se li atorga per part de les famílies i dels docents. En línies generals (Comission des Écoles Catholiques de Montréal, 1991b), es creu que el treball dels agents ha d'afavorir el diàleg intercultural perquè es produeixi una comprensió més bona de les cultures i dels partenaires amb presència a l'escola i perquè es resolguin els problemes de comunicació existents entre els pares i l'escola, sorgits d'una incomprensió lingüística o d'un xoc cultural. El desenvolupament de les relacions interculturals a l'escola i l'harmonització dels valors d'aquesta amb els de les famílies apareixen, igualment, implícits en el treball diari de l'agent. Això sí, aquestes tasques prenen més importància a l'educació secundària que a la primària. Per això, Mc Andrew i Hardy creuen totalment justificada la creació d'aquesta figura i la dedicació dels recursos humans i econòmics necessaris ${ }^{1}$.

1. A l'estudi de Mc Andrew i Hardy (1992), quan se'ls demana que descriguin la persona que treballa com a agent, la majoria en fan un retrat molt elogiós: una tercera part descriu l'agent com una persona altament responsable, molt implicada en el seu treball i amb una forta personalitat. Tot i que el perfil mitjà de l'agent és difícil de definir, ho fan a partir dels seus atributs personals, acadèmics i professionals. Quant a les característiques personals, es 
Respecte a la distinció entre els apel-latius, agents de liaison dels de milieu, cal assenyalar que en general hi ha dificultats per precisar els termes, sovint sembla que hi hagi una confusió entre tots dos. Cada centre escolar defineix les tasques i el terme (liaison o milieu) segons la percepció que té del seu treball. Contràriament al que la descripció de les tasques formals poden deixar entreveure, l'agent de milieu no està necessàriament assignat al centre de primària $\mathrm{i}$ l'agent de liaison al de secundària. Atesa la dificultat per diferenciar-los, la particularitat que hi varen trobar Mc Andrew i Hardy (1992) és que l'agent de milieu és una persona molt implicada en les activitats tant pedagògiques com culturals i recreatives de la institució escolar; mentre que l'agent de liaison es relaciona sols amb els pares quan ho demana la direcció o el professorat, tot això independentment del nivell educatiu en què es troben. Cal assenyalar també que en una escola de primària la presència d'un agent de milieu està supeditada a un equip d'agents de liaison que es troben sota la seva autoritat. Malgrat això, els autors de l'estudi, concentrant-se a establir alguna diferència, consideren que hi ha set models en aquesta diferenciació artificial de les dues figures; més concretament, descriuen quatre tipologies per a l'educació primària i tres més per a la secundària (vegeu també Garreta i Llevot, 1999). Evidentment, del mateix estudi es dedueix, pel que ja hem anat constatant, que hi haurà variacions significatives respecte al reclutament d'aquest personal, les condicions salarials, els horaris i els períodes de treball.

- En l'educació primària hi ha, almenys, quatre tipus d'agents: els primers són els que es limiten a realitzar trucades telefoniques, traduccions o a fer d'intèrprets lingüístics respecte a una comunitat cultural (model 1); el segon model estaria constituït pels que fan el mateix que els anteriors però que es dirigeixen a diverses comunitats o a totes les presents a l'escola (model 2); el tercer seria els que assumeixen diferents treballs complementaris que se sumen a les funcions mínimes; així, alguns treballen per donar a conèixer el sistema escolar als pares, promoure la matriculació a cursos de francès i facilitar la inserció en la societat d'acollida (model 3), i el quart va encara més lluny, perquè realitza intervencions més profundes, col-labora amb

constata que hi ha més dones que homes; oscil.len entre 30 i 55 anys; alguns han arribat recentment al Quebec, tot i que d'altres fa més de deu anys que hi són; hi ha persones d'orígens ètnics diversos, sobretot asiàtics del sud, haitians, llatinoamericans, libanesos i portuguesos; la formació és alta (des dels que estan fent la diplomatura fins a doctors); aquesta situació ja fa pensar en una variada situació socioeconòmica; i, finalment, n'hi ha molts que han estat docents en el seu país d'origen i d'altres provenen de l'administració. Sobre els possibles usuaris d'aquest servei, la majoria dels entrevistats no volen establir una priorització; sostenen que la integració de l'alumne necessita la col-laboració dels pares, l'adaptació de l'equip de l'escola, així com la implicació de l'alumne. Per contra, d'altres creuen que la intervenció amb la família seria l'essencial, i, finalment, aposten per fer-ho amb els docents. Tot i aquestes divergències, és possible trobar un cert consens sobre els dos eixos prioritaris del treball de l'agent, que podrien constituir els elements centrals del seu contracte, que són l'èxit escolar i la creació de lligams entre la família i l'escola. 
d'altres professionals i amb l'alumnat que presenta problemes específics i organitza activitats amb la intenció d'aproximar l'equip de l'escola als pares (model 4).

- En l'educació secundària es distingeixen tres models: el primer és calcat al segon model anterior, ja que a secundària sempre es treballa amb més d'una comunitat (model 5); el segon està constituït pels que ajuden l'equip de professionals de l'escola amb l'objectiu de facilitar l'èxit escolar de l'alumne i de la seva integració psicosocial, i participen també en activitats socioculturals que pretenen afavorir l'aproximació entre comunitats (model 6); l'últim model d'agents intervé amb alumnat de tots els orígens per solucionar els conflictes i les tensions interètniques que es puguin ocasionar (model 7).

A més, dins aquests models, cadascuna de les escoles beneficiàries del servei de l'agent proporciona una definició específica i defineix les tasques - necessitats lingüístiques, culturals, etc.- - que es detecten per integrar els grups d'alumnes minoritaris al sistema escolar. Quant a l'impacte del treball dels agents, se segueix insistint, malgrat les dificultats, en l'impacte positiu d'aquesta mesura. Concretament, s'afirma que l'alumne se sent més segur, s'adapta millor al nou medi escolar, quan pot dialogar amb un adult que parli la seva llengua i pertanyi a la seva comunitat. Entre les dificultats es menciona que, en certs medis, l'adaptació de l'agent al sistema escolar i a l'equip professional és més lenta del previst, a part que la figura no sempre és valorada positivament per l'esmentat equip (Mc Andrew i Hardy, 1992).

\subsection{Els agents del Quebec: una experiència reeixida en retrocés}

En aquesta mateixa direcció, els resultats del nostre treball de camp realitzat a la ciutat de Montreal $^{2}$ apunten el desig de seguir associant els agents amb els canvis en el currículum escolar i en les relacions entre escola i comunitat. En aquest sentit, el retrat ideal de l'agent, tot i que la realitat segueix sent molt diversa i difícilment agrupable, és dibuixat com el d'un especialista de la relació entre l'escola i la comunitat ètnica en un medi pluricultural. A més, respecte a si aquesta figura havia de pertànyer a les "comunitats culturals» ${ }^{3}$ o podia

2. Concretament, hem realitzat dues estades de recerca, en les quals, a part d'una anàlisi bibliogràfica i documental sobre el tema, hem pogut entrevistar 19 professionals (16 docents -8 de primària i 8 de secundària— i 3 agents) del quartier Côte-des-Neiges (considerat el més pluriètnic) de Montreal (per ampliar, vegeu Llevot, 2002). Així, també hem participat en dos projectes d'investigació que porten el títol de Politiques d'intervention du gouvernement québécois destinées aux enfants défavorisés des communautés culturelles i Résistance à la diversité ethnique et culturelle au sein des institutions scolaires realitzats l'any 1997 i 1998, respectivament, adscrits al Groupe de Recherche sur l'Ethnicité et l'Adaptation au Pluralisme en Education, del Centre d'Etudes Ethniques de la Universitat de Montreal.

3. Concepte sovint utilitzat en els texts de l'Administració. Segons l'Enoncé (Ministère des Communautés Culturelles et de l'Immigration, 1990), aquesta expressió s'utilitza per 
ser un agent québécois de vieille souche $e^{4}$, les respostes són diverses: uns es decanten per l'origen cultural i suggereixen que la pertinença a un grup ètnic sembla que afavoreixi la possibilitat d'una relació i un enteniment millors amb la "part més feble», a més, veuen com a avantatges: el domini de diverses llengües (sovint, entre tres i quatre); la pròpia experiència d'integració social i escolar que pot afavorir, considerablement, la comunicació amb els pares i els alumnes nouvinguts; el coneixement de les informacions de les característiques socioculturals de la seva pròpia ètnia, fet que pot facilitar la resolució de problemes d'interpretació cultural... Això sí, tot l'anterior es fa reconeixent que la sola pertinença ètnica no constitueix en cap cas un criteri de competència, ja que s'ha de complementar amb un perfil professional en correspondència a les necessitats per les quals l'agent és contractat. Els que no ho creuen així i es decanten per un quebequès de soca-rel, justifiquen la seva resposta de la forma següent: pot recórrer a una xarxa d'intèrprets lingüístics per entendre's amb els pares minoritaris i, per tant, no cal que conegui tantes llengües; la pertinença a la cultura dominant afavorirà la integració dels alumnes i dels progenitors; és una opció preferible en una escola pluriètnica, ja que seria impossible tenir mediadors de totes les ètnies i/o orígens, i, com a darrera raó, consideren que les qualitats personals s'han de prioritzar a l'origen ètnic o cultural de l'interlocutor.

Quant a les tasques, haurien de consistir i centrar-se a aportar informació als diferents actors escolars (professorat, direcció, equips d'assessorament, entre altres) sobre els alumnes minoritaris i ajudar-los a preparar activitats pedagògiques i projectes escolars, a fi de servir de facilitadors de recursos (personnes ressources) per a les escoles. Aquestes accions es completen amb un conjunt d'intervencions puntuals entorn de l'alumnat en risc —els problemes d'aquests alumnes són de diversos ordres: dificultats familiars, pedagògiques, d'integració escolar $\mathrm{i}$, fins i tot, delinqüència a l'etapa de secundària-. Pel que fa a actuar d'intermediari entre l'escola i la família ${ }^{5}$, es tracta de la traducció o la interpretació d'informacions escrites o verbals en llengua francesa i en les diferents llengües de les minories ètniques o l'establiment d'una comunicació amb els pares per crear un lligam amb ells. En menor mesura, alguns agents participen i preparen les reunions amb els pares o recluten voluntaris entre les famílies per cooperar i participar en activitats del centre.

Per anar cloent, un dels debats oberts al Quebec (i avui a Catalunya respecte als mediadors interculturals) és si els agents han de ser professionals

designar les persones que arriben de fora, és a dir, de procedència cultural no francesa, britànica o autòctons.

4. Hem de fer constar que el grup d'agents de Montreal no representa tampoc la diversitat ètnica de la clientela escolar de la ciutat (que en algunes escoles, que hem visitat, aquesta presència representa més de setanta-cinc comunitats escolars), ja que alguns grups culturals, com ara grecs, italians, entre altres, no es beneficien d'agents de la seva comunitat cultural.

5. Pel que fa a les modalitats de contacte amb les famílies, la majoria recorren a l'entrevista telefonica, individual o en gran grup a l'escola. No s'observa gaires intervencions a les esferes privades o comunitàries, ja que el despatx de l'agent és dins la institució escolar. 
amb el reconeixement, la formació, la contractació... que això representa. En el cas quebequés, aquesta figura pateix la mateixa indefinició i heterogeneïtat que el seu nom. Així, per exemple, a la primària estan pagats al dia i considerats com a tècnics, mentre que els de la secundària — alguns (no tots) estan considerats professionals no docents i reben un sou més elevat per una tasca equivalent als seus col-legues de primària (vegeu, entre altres, Mc Andrew i Hardy, 1992; Llevot, 2002). Això sí, en la nostra part empírica hem pogut detectar dos perills en la "professionalització» d'aquesta figura a les institucions educatives: el de convertir-se en un missatger a càrrec de l'equip directiu, així com el d'esdevenir un «apagafocs» quan es plantegi qualsevol problema amb la comunitat cultural de referència i abandonar una fita més àmplia. Respecte a la formació, en general es creu que no n'hi ha prou amb el fet de pertànyer a un grup etnocultural i ser reconegut per «les parts» com a «tercera persona» que pot mediar, sino que també cal tenir-ne d'específica. Per això, hi ha molt interès per rebre una formació inicial i contínua que ajudi en les intervencions i, per altra banda, el suport i la supervisió de la seva tasca. Resulta també interessant el desig d'intercanviar experiències i coordinar-se amb altres que treballin en el camp educatiu, per intercanviar orientacions, punts de vista, etc., així com rebre un perfeccionament permanent.

A manera de síntesi, aquestes figures, amb diferents perfils en funció del treball que acaben realitzant (recordem que se n'han establert fins a set models diferents) i, en conseqüència, amb diferents graus d'efectivitat en el seu objectiu inicial, han suposat canvis positius en el context escolar. Particularment, s'ha valorat la tasca feta en l'adaptació del currículum a les necessitats dels usuaris a través de la creació de vies de comunicació entre escola i comunitat. Malgrat això, no podem dir que l'experiència resulti positiva en tota la seva amplitud, de fet, han existit i existeixen distàncies entre equip escolar i agents que s'han de superar, així com intervencions que, per l'excés de treball, per les directrius que reben, etc., converteixen el que hauria de ser un mediador en un simple traductor o interventor de problemes puntuals (un «apagafocs»), de forma que la dinàmica del centre no s'enriqueix d'aquesta diversitat. A més a més, a inicis del segle XXI, els problemes pressupostaris estan limitant les actuacions i no sols el desenvolupament de la seva presència, sinó també el seu manteniment, ja que, com manifesten els docents i agents entrevistats, es troba en clar retrocés.

\section{A tall de reflexions}

El Quebec ha estat, malgrat les distàncies, un referent per a Catalunya, sobretot en la qüestió lingüística. I val a dir que, des de fa alguns anys, Catalunya resulta interessant per al Quebec com un model educatiu diferent —amb una única estructura, no com al Quebec que és doble en funció de la llengua i per ser una societat no dividida (vegeu Mc Andrew i Gagnon, 2000)-. Però per a nosaltres resulta interessant el Quebec per l'evolució que ha sofert 
cap a l'educació intercultural, i avui en dia cap a l'educació per a la ciutadania ${ }^{6}$. Per això, sembla convenient la utilització del Quebec com a referent per l'evolució que ha realitzat aquesta província canadenca en els últims vint anys i els desafiaments que ha viscut per ser una societat multicultural (que té el seu reflex a l'escola), així com els que es creu que haurà d'afrontar en un proper futur.

A Catalunya, la mediació intercultural s'ha anat desenvolupant considerablement els darrers anys, exemple d'això n'és el nombre d'experiències que s'hi realitzen (especialment pel que fa al col-lectiu immigrant —un primer pas seria els traductors mediadors que contracta el Departament d'Ensenyament per al període de preinscripció i matriculació dels alumnes nouvinguts en edat d'escolaritat obligatòria) i de cursos de formació de mediadors (vegeu Llevot, 2002). Aquestes iniciatives han de tenir presents els èxits i fracassos d'experiències semblants, de forma que no es caigui en els mateixos errors (per exemple, prenent rols de missatger, apagafocs...) i s'aprofiti tot el potencial real i transformador de la figura del mediador intercultural (creant i transformant les relacions entre les parts). Tot i que el Canadà no és l'únic indret on s'ha dut a terme (França, Itàlia, Bèlgica, etc. també ho han fet), l'experiència viscuda en les diferents ciutats presentades, i la de Montreal en particular, ens fa veure la llum i l'ombra de la mediació intercultural. Recordem com el naixement local de la figura i les múltiples necessitats que cal resoldre han suposat l'existència de models variats que costa definir de forma coherent. L'avantatge d'aquesta diversitat és també inconvenient quan no es reconeix què pot fer aquesta figura, quina formació ha de tenir, en quines condicions laborals ha de treballar (professional, voluntari...), etc. Com es pot veure, moltes d'aquestes qüestions les estem plantejant ara mateix a l'Estat espanyol, on la mediació intercultural creix a passes agegantades i no sempre de la forma més «adequada».

\section{Bibliografia}

BANKS, J.A.; LYNCH, J. (1986). Multicultural Education in Western Societies. Nova York: Praeger.

Beauchesne, A. (1987). Les agents de liaison de Montréal, Toronto et Vancouver. Scherbrooke: Faculté d'Éducation. Université de Sherbrooke/Éditions du CRP, Col-lectiu de Recherches Interculturelles.

Commission des ÉCOles CaTHOliques DE MONTRÉAl (1987). Rapport annuel de l'Opération Renouveau. Services des études. Quebec: CÉCM.

6. M. Mc Andrew i J. Rossell (2000), en la política d'integració escolar i d'educació intercultural, distingeixen tres fases que es corresponen a la dinàmica identificada en altres contexts per Banks i Lynch (1986): 1) la diversitat cultural produïda per les successives onades migratòries es percep com un problema lingüístic; 2) es creu necessari reconèixer i valorar la diversitat lingüística i cultural; 3) es realitza l'adaptació institucional al pluralisme —que els autors coincideixen a afirmar que encara no ha acabat. 
- (1991a). Mémoire des écoles catholiques de Montréal sur l'Énoncé de politique en matière d'immigration et d'intégration du Ministère des Communautés Culturelles et de l'Immigration. Quebec: CÉCM.

- (1991b). Le programme d'enseignement des langues d'origine. Montreal: CÉCM, Office des Relations Interculturelles.

CONSEIL SCOLAIRE DE L'Île DE MONTRÉAL (1991). «Les enfants des milieux défavorisés et ceux des communautés culturelles». Montreal: Conseil Scolaire de l'Île de Montreal (document inèdit).

Garreta, J. (2000). Diversidad cultural y educación en Quebec. Lleida: Milenio, Col.lecció Educació, sèrie Estudis, 1.

- (2002). «El miratge intercultural. L'escola de Catalunya davant la diversitat cultural». Lleida: Universitat de Lleida (document inèdit).

- (2003). El espejismo intercultural. La escuela de Cataluña ante la diversidad cultural. Madrid: CIDE, Ministerio de Educación, Cultura y Deporte.

GARRETA, J.; LLEVOT, N. (1999). «Los mediadores culturales: puente entre progenitores de las minorías étnicas y la institución escolar». Revista de Pedagogía Social. Monográfico de educación intercultural, núm. 1. Múrcia: Àrea de Pedagogia Social. Universitat de Múrcia, p. 95-15.

Helly, D. (1996). Le Québec face à la pluralité culturelle, 1977-1994. Quebec: Presses de la Université du Laval.

LAPERRIÈRE, A. (1983). L'intégration socio-scolaire des enfants immigrants dans les écoles de milieux socio-économiquement faibles: une recherche exploratoire. Montreal: Conseil Scolaire de l'Île de Montréal.

LATIF, G. (1989). L'école québécoise et les communautés culturelles. Quebec: Ministère de l'Éducation.

Llevot, N. (2002). Els mediadors interculturals a les institucions educatives de Catalunya. Lleida: Departament de Pedagogia i Psicologia. Universitat de Lleida (tesi doctoral).

MC ANDREW, M. (1993). L'intégration des élèves de minorités ethniques quinze ans après l'adoption de la loi 101: Quelques enjeux confrontant les écoles publiques de langue française de la region montréalaise. Montreal: Ministère des Communautés Culturelles et de l'Immigration de l'Éducation.

Mc Andrew, M.; GagnOn, F. (dir.) (2000). Relations ethniques et éducation dans les sociétés divisées. Montreal/París: L'Harmattan, Col-lecció Espaces Interculturelles.

MC ANDREW, M.; HARDY, J.Y. (1992). «Les agents de liaison et les agents de milieu. Un bilan». Montreal: Centre d'Études Ethniques (document inèdit).

MC ANDREW, M.; Rossell, J. (2000). «Inmigración y educación intercultural en quebec: programas y debates». Revista Española de Educación Comparada, núm. 0. Madrid: Universidad Nacional de Educación a Distancia/Sociedad Española de Educación Comparada, p. 259-284.

Ministère DE L'ÉDUCATION (1997). Réforme de l'éducation. Quebec: Gouvernement du Québec.

Ministêre des Communautés Culturelles et de l'Immigration (1990). Enoncé de politique en matière d'immigration et d'intégration. Quebec: Ministère des Communautés Culturelles et de l'Immigration. 